\title{
¿HA SIDO ESPAÑA PAÍS PARA VIEJOS DURANTE LA EMERGENCIA SANITARIA DE COVID-19?
}

Has Spain been a country for old men during the health emergency of COVID-19?

\author{
MIGUEL ÁNGEL PRESNO LINERA \\ Universidad de Oviedo' \\ presnolinera@gmail.com
}

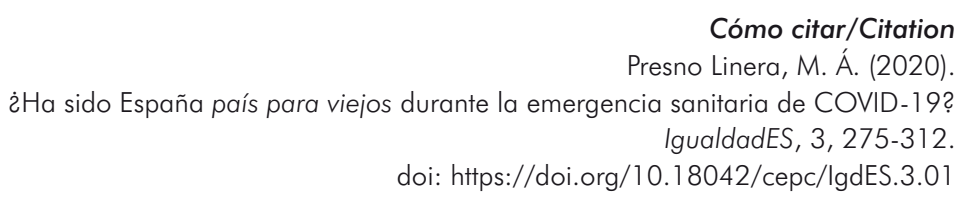

(Recepción: 24/06/2020; aceptación tras revisión: 06/10/2020; publicación: 18/12/2020)

\begin{abstract}
That is not a country for old men [...]
An aged man is but a paltry thing,

A tattered coat upon a stick, unless

Soul clap its hands and sing, and louder sing

For every tatter in its mortal dress,

Nor is there singing school but studying

Monuments of its own magnificence;

And therefore I have sailed the seas and come

To the holy city Byzantium.
\end{abstract}

William Butler Yeats, Sailing to Byzantium (1928).

\footnotetext{
$1 \quad$ Email: presnolinera@gmail.com. En http://presnolinera.wordpress.com he publicado diversas entradas sobre esta cuestión desde el 9 de marzo. Este trabajo se entregó el 20 de julio de 2020 y ha sido objeto de varias modificaciones en meses posteriores gracias a las sugerencias de quienes lo revisaron a efectos de su eventual publicación.
} 


\section{Resumen}

Las personas de mayor edad ha sido las más afectadas por la epidemia de COVID-19. En el presente trabajo se analiza si las medidas adoptadas por las diferentes administraciones públicas durante la emergencia sanitaria para proteger su vida y su salud han tenido en cuenta, cuando eso ha sido posible, su autonomía personal y su propia salud física y psíquica, en especial cuando se ha tratado de personas mayores que viven en residencias.

\section{Palabras clave}

COVID-19; crisis sanitaria; emergencia sanitaria; estado de alarma; personas mayores; grupos vulnerables; derecho a la salud; libertad de circulación; confinamiento.

\section{Abstract}

The elderly people have been hardest hit by the COVID-19 epidemic. This paper analyses whether the measures to protect their lives and health taken by the different public administrations during the health emergency have taken into account, where possible, their personal autonomy and their own physical and mental health, especially when they have been regarded as people living in Care Homes for the elderly.

\section{Keywords}

COVID-19; health crisis; health emergency; state of alarm; elderly people; vulnerable groups; right health; freedom of movement; confinement. 


\section{SUMARIO}

I. INTRODUCCIÓN: ¿̇ES ESPAÑA UN PAÍS DE VIEJOS? II. BREVE RECORDATORIO: LA EDAD NO PUEDE SER MOTIVO DE DISCRIMINACIÓN. III. APROXIMACIÓN A LA PROTECCIÓN JURÍDICA DE LAS PERSONAS MAYORES. IV. EL DERECHO A LA SALUD DE LAS PERSONAS MAYORES Y SU ACCESO A LOS TRATAMIENTOS SANITARIOS Y A LA ATENCIÓN HOSPITALARIA DURANTE LA PANDEMIA DE LA COVID-19. V. LOS LÍMITES A LA LIBERTAD DE CIRCULACIÓN DE LAS PERSONAS MAYORES DURANTE LA VIGENCIA DEL ESTADO DE ALARMA POR COVID-19: 1. El confinamiento generalizado de las personas mayores hasta el 2 de mayo de 2020. 2. Los límites adicionales a las personas mayores residentes en centros sociosanitarios: prohibición de salir de los centros y de recibir visitas. VI. A MODO DE BREVE CONCLUSIÓN. BIBLIOGRAFía.

\section{INTRODUCCIÓN: ¿̇ES ESPAÑA UN PAÍS DE VIEJOS?}

El 12 de marzo de 2020, dos días antes de la declaración del estado de alarma, se publicó el informe Un perfil de las personas mayores en España, 2020. Indicadores estadísticos básicos ${ }^{2}$, que, en palabras de sus autores, "presenta una serie de indicadores demográficos, de salud, económicos y sociales que proporcionan una visión general de la situación, características y comportamientos de las personas mayores [de 65 años] en España, así como de los cambios que han experimentado en los últimos años». Mencionaremos algunos datos de relevancia para el asunto al que dedicamos estas páginas sobre los que se volverá más adelante.

- Así, a 27 de diciembre de 2019 había 9057193 personas mayores, un $19,3 \%$ sobre el total de la población (47 026208). Los octogenarios ya representan el 6,1\% de toda la población. Los centenarios eran 16303.

- El mayor número de personas mayores se concentra en municipios urbanos: en los dos más grandes de España (Madrid y Barcelona) viven 1011955 , más que en los 5877 municipios rurales.

2 Pérez et al. (2020). A este informe se refiere, como fuente documental, el Defensor del Pueblo (2020: 5). Véase también el informe de HelpAge España (2020). 
- Asturias, Castilla y León, Galicia, País Vasco, Cantabria y Aragón son las comunidades autónomas más envejecidas con proporciones de personas mayores que superan el $21 \%$. Baleares, Murcia, y Canarias son las comunidades con proporciones más bajas, por debajo del $16 \%$.

- En 2018 las mujeres en España tenían una esperanza de vida al nacer de 85,9 años y los hombres de 80,5 años (83,2, ambos sexos), según las últimas Tablas de mortalidad del INE.

- Más de la mitad de todas las estancias causadas en hospitales son de población mayor: en 2018 ya fueron el 57,9\%, porcentaje que sigue aumentando; de un total de 40563057 estancias hospitalarias (fecha de alta menos la de ingreso, no computándose estancias iguales a cero días), 23474841 correspondieron a personas mayores. Del total de altas de personas mayores, las enfermedades circulatorias $(19,8 \%)$, respiratorias $(17,2 \%)$, digestivas $(12,1 \%)$ y neoplasias $(10,9 \%)$ son las causas más frecuentes de asistencia hospitalaria. Le siguen en importancia las lesiones, las enfermedades genitourinarias y las del sistema osteomuscular. Un $22,2 \%$ de personas mayores tiene obesidad, y otro $41,5 \%$ sobrepeso.

- El patrón de edad de la mortalidad de la población en su conjunto está determinado por las causas de muerte de los mayores, que suponen el 86,0\% de todos los fallecidos en España (2018). En 2018, la principal causa de muerte entre los mayores está relacionada con enfermedades del aparato circulatorio (109984 fallecimientos). El cáncer (tumores) es la segunda causa (85812 fallecidos), y en tercer lugar, a distancia, se encuentran las muertes por enfermedades respiratorias (50 469).

- En 2019 la pensión media del sistema fue de 991 euros mensuales. Las pensiones de las mujeres son más bajas que las de los hombres, debido a sus diferentes carreras laborales, ocupaciones, o por tener otro tipo de pensiones (viudedad, etc.).

- El gasto fundamental de un hogar donde residen personas mayores es el mantenimiento de la propia vivienda (agua, electricidad, y otros gastos), cuya proporción suele ser más alta que en el resto de grupos de edad, alrededor del $45 \%$ de los gastos. El capítulo alimentación es el segundo en importancia. Ambas cosas están relacionadas con unos ingresos menores en términos absolutos.

- La posición económica de los mayores ha mejorado relativamente en los años de crisis económica; su proporción en riesgo de pobreza es de un $15,6 \%$ (2018), inferior a la del resto de los españoles. Aparentemente han evitado lo peor de la crisis económica iniciada en 2008, pero desde 2015 aumenta de nuevo el riesgo de pobreza. 
- Durante la vejez, y hasta las edades muy avanzadas, la edad aumenta la probabilidad de vivir en soledad. Ha habido en los últimos años un incremento de los hogares unipersonales en personas de 65 y más años, aunque las proporciones son todavía menores que en otros países. La proporción es mayor entre las mujeres que entre los hombres (2018: 31,0\% frente a $17,8 \%)$ pero en estos ha habido un aumento notable en los últimos años.

- En España hay 4,1 plazas de residencia por cada 100 personas mayores; en total, 372985 plazas (2019). Se desconoce el nivel de ocupación, pero puede situarse entre el 75-80\%.

- A partir de los 55 años hay un descenso en los porcentajes de personas que utilizan internet. Se percibe una brecha digital entre los mayores y el resto de la población. Sin embargo, la brecha se reduce rápidamente en los últimos años, especialmente por a la llegada a estas edades de personas que ya utilizaban internet previamente, más que por una alfabetización digital de los ya mayores; en 2007 la brecha era de 78,6 puntos porcentuales entre el grupo de edad más conectado (16-24 años) y el de los mayores (65-74 años); en 2019, se ha reducido a 35,5 puntos.

España no es, como no lo es país alguno en estos momentos, un país de viejos e, incluso, está por debajo $(19,3)$ de la media de la Unión Europea a 27 $(20,3)$ : en dicho entorno los países con mayor número de personas mayores en el año 2019 fueron Alemania (17,9 millones), Italia (13,8), Francia (13,5) y España $(9,1)$. En cifras relativas el orden cambia: Italia $(22,8 \%)$, Grecia $(22,0 \%)$, Portugal y Finlandia $(21,8 \%)$ y Alemania $(21,5 \%)$ son los países más envejecidos.

En todo caso, en España las personas mayores de 65 años suponen casi la quinta parte de la población y se prevé que en el año 2050 ese porcentaje se haya duplicado. Además, como se ha visto con los datos anteriores, se trata del grupo de personas que tiene más problemas de salud y que, por tanto, más atención médica y hospitalaria requiere; adicionalmente, su situación económica, en general, no es, muy boyante.

Una cuestión que tener en cuenta en relación con las personas mayores que viven en residencias sociosanitarias, públicas y privadas, es la situación legal, organizativa y prestacional de las mismas, aspectos que han venido ocupando y, para decirlo con todas las palabras, preocupando a diversas instituciones, singularmente al Defensor del Pueblo (2020: 17-19), donde se recogen una serie de conclusiones que resumiremos en las siguientes líneas ${ }^{3}$ :

3 En particular sobre la gestión, véase Pino et al. (2020a). A modo de resumen, Pino et al.(2020b). 
Perdura una gran dispersión normativa sobre los requisitos que deben reunir los centros residenciales para su acreditación y posterior autorización de funcionamiento. En consecuencia, para solventar esta situación se requiere que las comunidades autónomas realicen un importante esfuerzo de actualización y armonización.

No existe un mecanismo eficaz comúnmente compartido entre todas las administraciones para recopilar datos que permitan realizar estadísticas fiables que se actualicen periódicamente respecto de los recursos de atención residencial disponibles, tanto en el plano autonómico como estatal. De esta forma se podrán realizar estrategias de atención a las personas mayores más adecuadas.

Se carece de un número suficiente de plazas públicas y concertadas de atención residencial para atender los derechos subjetivos derivados de la Ley 39/2006, de promoción de la autonomía y atención a la dependencia. Por tanto, se requiere de un significativo esfuerzo presupuestario para dotar más plazas.

Es necesario un número suficiente de personal para prestar servicios en los centros residenciales. Por tanto, se requiere una profunda revisión al alza de las ratios de personal de atención directa para mejorar la calidad asistencial, pues se han quedado manifiestamente desfasadas. Los usuarios con dependencia son más y su dependencia es mayor y requieren una atención correcta y plenamente respetuosa con sus derechos.

Resulta importante mejorar la cualificación del personal que presta sus servicios en el sistema residencial. Las administraciones deben fomentar e impulsar planes de formación profesional específica para el desempeño de los puestos de trabajo que tienen encomendados.

Un modelo de residencias propiamente sociosanitario, con atención médica y de enfermería más amplia y extensa, en España no está regulado ni ha sido así organizado de forma general para todo el sistema. Sería útil estudiar su viabilidad y conveniencia.

Es imprescindible que las comunidades autónomas creen con urgencia, o en su caso incrementen adecuadamente, unos servicios de inspección suficientemente dotados de personal correctamente formado, para que puedan llevar a cabo su función de vigilancia de forma eficaz, para que los centros mantengan los requisitos normativos exigidos para su correcto funcionamiento y unos niveles adecuados de calidad en la prestación del servicio de atención residencial de mayores. También es muy recomendable que se aprueben planes periódicos de inspección de los centros con indicadores sobre calidad, trato inadecuado y buenas prácticas.

Es precisa una ley orgánica que delimite las circunstancias extraordinarias vinculadas a la salud y al deterioro físico y mental en las que las personas en edad avanzada pueden tener que asumir limitaciones al ejercicio y realización de algunos de sus 
derechos fundamentales, con especial referencia a la atención en centros residenciales y a las situaciones en las que excepcionalmente podrían adoptarse medidas extraordinarias de restricción de la libertad y otros derechos [...]

En definitiva, resultan necesarias reformas normativas de calado que garantice a los mayores el ejercicio de una serie de derechos y que se preste una mayor atención presupuestaria, formativa, dotacional e inspectora en los centros residenciales que permita hacer frente a toda una serie de retos que hoy tiene planteado este sector, y que con toda seguridad se incrementara en un futuro inmediato».

\section{BREVE RECORDATORIO: LA EDAD NO PUEDE SER MOTIVO DE DISCRIMINACIÓN}

Es bien sabido que en rigor el art. 14 de la Constitución española $(\mathrm{CE})^{4}$ no prohíbe cualquier trato diferenciado; sí, en palabras del Tribunal Constitucional (TC), el que introduzca

una diferencia entre situaciones que puedan considerarse iguales, sin que se ofrezca y posea una justificación objetiva y razonable para ello, pues, como regla general, el principio de igualdad exige que a iguales supuestos de hecho se apliquen iguales consecuencias jurídicas y, en consecuencia, veda la utilización de elementos de diferenciación que quepa calificar de arbitrarios o carentes de una justificación razonable. Lo que prohíbe el principio de igualdad son, en suma, las desigualdades que resulten artificiosas o injustificadas por no venir fundadas en criterios objetivos y razonables, según criterios o juicios de valor generalmente aceptados (STC 63/2011, de 16 de mayo, FJ 3).

En ese mismo fundamento jurídico se añade que

por lo que se refiere en concreto a la edad como factor de discriminación, este Tribunal la ha considerado una de las condiciones o circunstancias incluidas en la fórmula abierta con la que se cierra la regla de prohibición de discriminación establecida en el art. $14 \mathrm{CE}$, con la consecuencia de someter su utilización por el legislador como factor de diferenciación al canon de constitucionalidad más estricto 5 .

4 «Los españoles son iguales ante la ley, sin que pueda prevalecer discriminación alguna por razón de nacimiento, raza, sexo, religión, opinión o cualquier otra condición o circunstancia personal o social».

5 Cardona et al. (2019). 
El propio TC ya había dicho mucho tiempo atrás (STC 69/1991, de 8 de abril, FJ 4) que

la edad es, naturalmente, una circunstancia personal y como tal no puede ser razón para discriminación alguna [...] la prohibición contenida en el art. 14 de nuestra Constitución no puede ser entendida sin embargo de modo tan rígido que las circunstancias personales no puedan ser tomadas nunca en consideración por el autor de la norma o por quien la interpreta, cuando tales circunstancias son relevantes para la finalidad legítima, y en sí misma no discriminatoria, que la norma persigue.

Por su parte, la Carta de Derechos Fundamentales de la Unión Europea (CDFUE) ha incorporado a la edad de manera expresa como circunstancia que excluye el trato discriminatorio; así el art. 21 dispone que «se prohíbe toda discriminación, y en particular la ejercida por razón de sexo, raza, color, orígenes étnicos o sociales, características genéticas, lengua, religión o convicciones, opiniones políticas o de cualquier otro tipo, pertenencia a una minoría nacional, patrimonio, nacimiento, discapacidad, edad u orientación sexual» y, por citar un ejemplo jurisprudencial, el Tribunal de Justicia de la Unión Europea (asunto Mangold c. Helm, de 22 de noviembre de 2005) declaró que «el principio de no discriminación por razón de la edad debe ser considerado un principio general del Derecho comunitario» (apdo. 75) .

Dicho lo anterior, es necesario verificar si tales exigencias normativas de no discriminación por razón de edad tienen un adecuado correlato en la práctica y si las personas mayores en nuestro país no son un colectivo que sufra prácticas discriminatorias y para ello es necesario contar con unos datos que, en general, hoy todavía no se han recabado para, como se reclama en HelpAge España (2020: 33), se obtenga una imagen más precisa de la realidad que viven las personas mayores y así conocer las discriminaciones y dificultades a las que se enfrentan a la hora de ejercer sus derechos de modo que las intervenciones normativas y de políticas públicas se desarrollen lo mejor posible, cumpliendo así, además, con la obligación internacional del Estado español de incluir datos sobre las personas mayores en los informes sobre derechos humanos que realice para organismos internacionales.

6 Por citar un precedente más lejano en el tiempo, en Estados Unidos se aprobó en 1967 la Age Discrimination in Employment Act, que estableció la protección de los trabajadores de 40 años de edad o más frente a la discriminación por motivos de edad en la contratación, el ascenso, el despido y en los términos y condiciones del empleo. Sobre estas cuestiones en el ámbito internacional HelpAge España (2020: 10-12). 


\section{APROXIMACIÓN A LA PROTECCIÓN JURÍDICA DE LAS PERSONAS MAYORES}

El art. $50 \mathrm{CE}$ establece, como uno de los principios rectores de la política social y económica, que «los poderes públicos garantizarán, mediante pensiones adecuadas y periódicamente actualizadas, la suficiencia económica a los ciudadanos durante la tercera edad. Asimismo, y con independencia de las obligaciones familiares, promoverán su bienestar mediante un sistema de servicios sociales que atenderán sus problemas específicos de salud, vivienda, cultura y ocio» ${ }^{7}$.

No nos ocuparemos aquí del evidente contenido económico y social de este precepto y que ha sido objeto de desarrollo en diversas leyes, algunas de las cuales no tienen como destinatarios específicos a las personas que la CE sitúa en «la tercera edad», como la «Ley 39/2006 de promoción de la autonomía personal y atención a las personas en situación de dependencia» o el «Real Decreto Legislativo 1/2013 por el que se aprueba el texto refundido de la Ley General de derechos de las personas con discapacidad y de su inclusión social». Tanto una como otra norma se centran en la protección jurídica de las personas y los grupos vulnerables ${ }^{8}$.

Aceptando aquí la terminología «personas mayores»", es obvio que las mismas no están de suyo en una situación de vulnerabilidad, pero sí son más

Véase, con detalle, Flores Giménez (2019: 29-52); sobre la protección internacional, Cebada Romero (2019: 53-71).

8 Sobre la protección de las personas mayores vulnerables en el contexto de la COVID-19, Presno Linera (2020a: 54-65).

9 Explica Martínez Ques que «la terminología empleada para designar a las personas de edad es muy variada y heterogénea. Según el Comité de Derechos Sociales, Económicos y Culturales, en los documentos internacionales se opta por los términos: personas mayores, personas de edad avanzada, personas de más edad, tercera edad, ancianos y cuarta edad para los mayores de 80 años. Ese Comité opta por "personas mayores», como la Asamblea General de las Naciones Unidas, término que englobaría a las personas de más de 60 años. En el servicio estadístico Eurostat se consideran mayores las de 65 o más años. En otros ámbitos jurídicos se ha fijado una edad más temprana; así, la Convención Interamericana sobre la Protección de los Derechos Humanos de las Personas Mayores considera mayores a las personas a partir de los 60 años, «salvo que la ley interna determine una edad base menor o mayor, siempre que esta no sea superior a los 65 años» (art. 2) y el Protocolo a la Carta Africana sobre Derechos Humanos y de los Pueblos fija en África también esa edad en los 60 años (art. 1). En todo caso, no hay que perder de vista que, como se recuerda en el Informe de HelpAge España (2020: 7), la «decisión sobre cuándo se comienza a tratar a alguien como a una 
propensas a ello que personas más jóvenes, al menos en términos de grupo, por la mayor prevalencia de determinadas complicaciones de la salud ${ }^{10}$. Si sumamos a la circunstancia de la edad otros factores de vulnerabilidad, entonces su vida se complica de manera extraordinaria: por ejemplo, si tienen, además, algún tipo de discapacidad física y/o mental, si carecen de recursos suficientes, si viven en la calle, si son personas mayores que están presas, si tienen personas que dependen de ellas por razones de cuidados, económicas... En esta línea, la citada CDFUE dedica el art. 25 a las personas mayores y proclama que «la Unión reconoce y respeta el derecho de las personas mayores a llevar una vida digna e independiente y a participar en la vida social y cultural».

Es importante destacar esa exigencia de una vida digna e independiente para las personas mayores, entendida como una vida en la que no se encuentren en una posición de inferioridad respecto a otras personas y en la que puedan seguir autodeterminándose en la mayor medida posible. Cabría enlazar así el art. 25 CDFUE con el art. 10.1 CE que erige a la dignidad humana y al libre desarrollo de la personalidad como fundamentos del orden político y de la paz social, lo que en el caso de la dignidad implica, según la jurisprudencia constitucional, un minimun invulnerable que todo estatuto jurídico debe asegurar, de modo que, sean unas u otras las limitaciones que se impongan en el disfrute de derechos individuales, no conlleven menosprecio para la estima que en cuanto ser humano merece la persona (STC 120/1990, de 27 de junio, FJ 4). Por su parte, el libre desarrollo de la personalidad apunta a la maximización de la fundamentalidad de los derechos, tanto en el sentido de que extiende el haz de libertades disponibles directamente por el titular del derecho como en el de que estrecha el ámbito de actuación de los poderes públicos y, en particular, del legislador, al obligarle, cuando sea necesario, a que apruebe la legislación que permita el ejercicio del derecho y al predeterminar su contenido.

En otras palabras, y por lo que respecta a la dignidad, las personas mayores, como cualquier otra persona, deben disfrutar de unas condiciones mínimas para el ejercicio de sus derechos, lo que en su caso puede implicar la obligatoriedad por parte de los poderes públicos de adoptar las medidas necesarias para ello. El libre desarrollo de la personalidad en el caso de las personas mayores se convierte en un principio o mandato de optimización en

persona mayor está relacionada con cuestiones culturales. Frente a este malentendido, el Informe Mundial sobre el Envejecimiento y la Salud publicado por la Organización Mundial de la Salud (OMS) en 2015 muestra, en palabras de la entonces directora general, Margaret Chan, cómo "la pérdida de capacidad generalmente asociada con el envejecimiento solo se relaciona vagamente con la edad cronológica de una persona"».

Barranco Avilés (2014: 17-44). 
el sentido de que refuerza la preservación normativa — dimensión subjetiva de los derechos- a favor de dichas personas y lo hace frente al legislador y los demás poderes públicos, imponiendo una protección preferente de los comportamientos descritos de manera más o menos genérica y abstracta en los enunciados jurídicos constitucionales. Además, orientando la labor de desarrollo del legislador que, en cumplimiento de la dimensión objetiva de los derechos fundamentales, actúa como un elemento de fortalecimiento de la garantía de la libertad jurídico-subjetiva ${ }^{11}$.

\section{EL DERECHO A LA SALUD DE LAS PERSONAS MAYORES Y SU ACCESO A LOS TRATAMIENTOS SANITARIOS Y A LA ATENCIÓN HOSPITALARIA DURANTE LA PANDEMIA DEL COVID-19}

Hay que comentar recordando que el art. $43 \mathrm{CE}$ dispone que «1. Se reconoce el derecho a la protección de la salud. 2. Compete a los poderes públicos organizar y tutelar la salud pública a través de medidas preventivas y de las prestaciones y servicios necesarios. La ley establecerá los derechos y deberes de todos al respecto [...]». Es bien sabido que no se confiere a la salud la condición de derecho fundamental, es decir, no se configura como un apoderamiento jurídico (contenido del derecho) que la Constitución atribuye a un sujeto para que pueda defender, asegurar o ejercer determinadas expectativas (objeto del derecho) ${ }^{12}$.

Y ello a pesar de que nadie dudará de que es «fundamental» para las personas tener garantizada la protección de la salud. Simplemente no es derecho fundamental porque la CE no lo sitúa en esa posición normativa suprema; su configuración jurídica la encomienda por completo al legislador y el individuo solo podrá alegar ese derecho en los términos dispuestos en la ley (art. 53.3 CE). En segundo término, esta ubicación sistemática determina que la regulación de la protección de la salud compete a la ley ordinaria — no a la orgánica- y dicho principio rector no está garantizado por un procedimiento preferente y sumario ante los tribunales ordinarios ni por el recurso de amparo ante el TC.

11 Un ejemplo de lo que se está diciendo lo encontramos en el asunto resuelto por el Tribunal Europeo de Derechos Humanos, el 25 de julio de 2017, en el caso Maria Ivone Carvalho c. Portugal.

12 Más extensamente, Presno (2018: 34-44); también García Amez (2018: 141-151); Gómez Sánchez (2011: 3-17); León Alonso (2010); Rey Martínez (2018: 281-296), y Tenorio Sánchez (2018: 433-446). 
Dicho lo anterior, es obvio que la inclusión de la protección de la salud en el texto constitucional no es algo baladí: en primer lugar, porque se hace un reconocimiento general de los beneficiaros como se deduce del empleo de la expresión «se reconoce»; en segundo lugar, porque se incluye un mandato claro: "Compete a los poderes públicos organizar y tutelar la salud pública a través de medidas preventivas y de las prestaciones y servicios necesarios». Por ello, cabría hablar de la salud como principio activo de parte de las conductas protegidas por varios derechos fundamentales, pues es la salud la que ofrece la condición necesaria para constituir derechos tales como el derecho a la vida, el derecho a la integridad física y moral, y el derecho a la intimidad personal.

En esta línea, es conocida la jurisprudencia del TEDH según la cual la ausencia de cuidados médicos apropiados de la que resulta la muerte de una persona vulnera el art. 2 (derecho a la vida) del CEDH (asunto Valentín Câmpeanu c. Rumanía, 17 de julio de 2014), así como cuando el Estado no responde a las obligaciones positivas de protección de la salud y de prestación de una adecuada asistencia sanitaria que derivan de ese precepto allí donde esas obligaciones son exigibles (SSTEDH Oyal c. Turquía, de 23 de marzo de 2010, Mehmet Sentürk y BekirSentürk c. Turquía, de 9 de abril de 2013, Asiye Genc c. Turquía, de 27 de enero de 2015, entre otras). Por su parte, en la STC 48/1996, de 25 de marzo, se alude a «la protección de la salud como expresión del derecho a la vida» (FJ 3) y, poco antes, el TC ya había dicho que «[...] el derecho a que no se dañe o perjudique la salud queda también comprendido en el derecho a la integridad personal» (STC 35/1996, de 11 de marzo, FJ 3).

Pues bien, la protección de la salud como parte de la protección de la vida y la integridad física y moral (integridad personal) tiene un componente universal y se garantiza a todas las personas, sin que la edad pueda ser por sí sola un motivo de trato peyorativo en este ámbito. La propia Ley 33/2011, de 4 de octubre, General de Salud Pública, prevé que

todas las personas tienen derecho a que las actuaciones de salud pública se realicen en condiciones de igualdad sin que pueda producirse discriminación por razón de nacimiento, origen racial o étnico, sexo, religión, convicción u opinión, edad, discapacidad, orientación o identidad sexual, enfermedad o cualquier otra condición o circunstancia personal o social [...]. La enfermedad no podrá amparar diferencias de trato distintas de las que deriven del propio proceso de tratamiento de la misma, de las limitaciones objetivas que imponga para el ejercicio de determinadas actividades o de las exigidas por razones de salud pública.

Esta línea ya estaba apuntada, primero, en el Convenio Relativo a los Derechos Humanos y la Biomedicina, hecho en Oviedo el 4 de abril de 1997, cuyo art. 1 proclama que «las partes en el presente Convenio protegerán al 
ser humano en su dignidad y su identidad y garantizarán a toda persona, sin discriminación alguna, el respeto a su integridad y a sus demás derechos y libertades fundamentales con respecto a las aplicaciones de la biología y la medicina», y más tarde, en el art. 35 de la CDFUE: "Toda persona tiene derecho a acceder a la prevención sanitaria y a beneficiarse de la atención sanitaria en las condiciones establecidas por las legislaciones y prácticas nacionales. Al definirse y ejecutarse todas las políticas y acciones de la Unión se garantizará un nivel elevado de protección de la salud humana».

Entrando en la cuestión de la atención sanitaria a las personas mayores durante la crisis sanitaria derivada del COVID-19, el Real Decreto 463/2020, de 14 de marzo, por el que se declara el estado de alarma para la gestión de la situación de crisis sanitaria ocasionada por el COVID-19, contemplaba, en su art. 4.3, que «los actos, disposiciones y medidas [...] deberán prestar atención a las personas vulnerables. Para ello, no será precisa la tramitación de procedimiento administrativo alguno». Y entre esas personas vulnerables se encontraban, sin duda, las personas mayores con determinadas patologías previas, sobre las que la incidencia del virus se demostró enseguida especialmente agresiva ${ }^{13}$.

13 El 30 de marzo la Sección de Cardiología Geriátrica de la Sociedad Española de Cardiología publicó un documento en cuya introducción señala: «La población de mayor edad es especialmente vulnerable a la infección por COVID-19, así como a desarrollar procesos de mayor gravedad. Este aumento de morbi-mortalidad en paciente mayor se ha asociado tanto a las comorbilidades, especialmente la enfermedad cardiovascular (ECV), como a la situación de fragilidad que conlleva una respuesta inmunológica más pobre [...]. Siendo España uno de los países más envejecidos a nivel mundial, el COVID-19 se ha convertido en una emergencia geriátrica a la que nos enfrentamos hoy en día [...]» Más adelante recuerda que "en España, en menos de 30 años se ha duplicado el número de personas mayores de 65 años, siendo alrededor del $17 \%$ de la población total, con más de 7 millones, de las que aproximadamente un $25 \%$ son octogenarias. La población de edad avanzada presenta una mayor susceptibilidad a la infección y a las formas más graves de la misma [...] los pacientes de edad avanzada con cardiopatía son especialmente vulnerables por tres motivos: son pacientes en riesgo de descompensación (en mayor o menor medida en función de la situación de su patología $\mathrm{CV}$ ), constituyen un grupo de riesgo elevado para la infección por lo que las medidas de aislamiento deben ser especialmente estrictas, y tienen una peor accesibilidad a las posibilidades de telemedicina (dificultades en la comunicación telefónica, no acceso o desconocimiento de nuevas tecnologías...). Es por ello por lo que debemos hacer un esfuerzo por cuidar a este grupo poblacional en la situación actual aún con las limitaciones descritas, actuando en estos niveles de vulnerabilidad [...]. Dentro de los pacientes de edad avanzada, las personas institucionalizadas constituyen un grupo 
La «Orden SND/265/2020, de 19 de marzo, de adopción de medidas relativas a las residencias de personas mayores y centros sociosanitarios, ante la situación de crisis sanitaria ocasionada por el COVID-19», incluye un preámbulo donde se puede leer:

Los mayores, las personas con discapacidad u otros usuarios de residencias y otros centros sociosanitarios se encuentran en situación de vulnerabilidad ante la infección COVID-19 por varios motivos, como son entre otros, que habitualmente presentan edad avanzada; patología de base o comorbilidades; y su estrecho contacto con otras personas, como son sus cuidadores y otros convivientes... La propagación del COVID-19 entre personas vulnerables que viven en residencias de mayores, se está observando en los últimos días, por lo que es necesario avanzar en la adopción de medidas organizativas y de coordinación, orientadas a reducir el riesgo de

especialmente vulnerable, máxime cuando en muchos casos las residencias están siendo aisladas por focos de COVID-19 [...]» (disponible en: https://bit.ly/36gnHf]).

En esta misma línea hay varios documentos de interés de la Sociedad Española de Geriatría y Gerontología, que ya el 5 de marzo publicó unas «Recomendaciones a residencias de mayores y centros sociosanitarios para el COVID-19", donde se advertía que «hasta donde conocemos, el SARS-CoV-2 afecta de forma más grave a mayores de 65 años con patología cardiovascular previa (sobre todo hipertensión e insuficiencia cardíaca) y en menor medida con patología respiratoria crónica y diabetes. La mortalidad aumenta con la edad [...]. Los residentes y usuarios de los centros sociosanitarios se encuentran en una situación de vulnerabilidad ante la infección por COVID-19 por varios motivos: habitualmente presentan patología de base o comorbilidades. Suelen presentar edad avanzada. Tienen contacto estrecho con otras personas (sus cuidadores) y otros convivientes. Suelen pasar mucho tiempo en entornos cerrados y con población igualmente vulnerable». Más adelante se dice que «si una persona clasificada como contacto de un caso probable o confirmado cumple criterios de caso en investigación, se informará a las autoridades de salud pública y se realizará el seguimiento según lo establecido por las mismas. No es necesario su traslado al centro sanitario si su estado general es bueno» (la cursiva es nuestra). Los documentos, alguno de los cuales será citado en el cuerpo del texto de este trabajo, están disponibles en: https://www.segg.es/actualidad-segg/covid-19.

Desde el punto de vista de los cuidados, también deben mencionarse, entre otros documentos, las «Propuestas de la Mesa Estatal por los Derechos de las Personas Mayores con medidas de actuación urgente ante el grave riesgo para los derechos y la vida de las personas mayores ante la COVID-19», de 26 de marzo; el «Plan mundial de respuesta humanitaria de Naciones Unidas para la COVID-19 y personas mayores», de 4 de mayo, y el «Segundo documento de propuestas de la Mesa Estatal por las Personas Mayores ante la pandemia de la COVID-19 para crear un nuevo modelo de atención y cuidados en el futuro", de 7 de mayo, todos disponibles en: https://bit.ly/2U3rmba. 
contagio así como a tratar de la forma más adecuada a las personas que sufran esta enfermedad...

Y su apartado segundo prevé las «medidas relativas a la ubicación y aislamiento de pacientes COVID-19 en las residencias de mayores y otros centros sociosanitarios» ${ }^{14}$. En apartados posteriores se regulan las medidas sobre limpieza de los centros, profesionales sanitarios y sobre «diagnóstico, seguimiento y derivación COVID-19», pero no se contempla criterio alguno en relación con el ingreso hospitalario de los mencionados pacientes y los eventuales triajes ${ }^{15}$, algo que sí abordaban, en la misma fecha, las «Recomendaciones de la Sociedad Española de Geriatría y Gerontología (SEGG) sobre decisiones éticas e ingreso en UCI en situación de crisis COVID-19», que, entre otras cosas, propone en primer lugar:

Priorizar: la maximización de la supervivencia al alta hospitalaria, la maximización del número de años de vida salvados y la maximización de las posibilidades de vivir de cada una de las etapas de la vida. Aún así, es importante enfatizar que la edad cronológica (en años) en ningún caso debería ser el único elemento a considerar en las estrategias de asignación» (la cursiva es nuestra).

14 «1. Los residentes de los centros en los que resulta de aplicación esta orden deben clasificarse en:

a) Residentes sin síntomas y sin contacto estrecho con caso posible o confirmado de COVID-19. b) Residentes sin síntomas, en aislamiento preventivo por contacto estrecho con caso posible o confirmado de COVID-19. c) Residentes con síntomas compatibles con el COVID-19. d) Casos confirmados de COVID-19. Esta clasificación debe realizarse en cada centro con carácter urgente, y a más tardar en el plazo de un día desde que se publique esta orden.

2. En el caso de que un residente presente infección respiratoria aguda leve, debe ser aislado del resto de residentes.

3. En el caso de que haya más un residente con infección respiratoria aguda leve, y no sea posible el aislamiento individual, puede recurrirse al aislamiento por cohorte.

4. En el caso de residentes con diagnostico COVID-19 confirmado, debe ser aislado del resto de residentes.

5. En el caso de que haya más de un residente con infección confirmada por COVID-19, puede recurrirse al aislamiento por cohortes.

6. En cualquier caso, estos residentes, casos posibles o casos confirmados de COVID-19, deben mantenerse aislados del resto de residentes [...]».

15 Véase De Miguel Beriain (2020: 229-241); en particular, Truog et al. (2020). 
En segundo lugar, recomienda un

triaje basado en la justicia distributiva: principio coste/oportunidad: admitir un ingreso puede implicar denegar otro ingreso a otra persona que puede beneficiarse más (evitar el criterio "primero en llegar, primero en ingresar»). Aplicar criterios estrictos de ingreso en UCI basados en maximizar el beneficio del bien común. Ante pacientes críticos con otras patologías criticas diferentes a la infección por COV19, se debe valorar ingresar prioritariamente el que más se beneficie. Estos principios se deberían aplicar manera uniforme a todas las personas - y no de forma selectiva a los de perfil geriátrico o con patologías crónicas- ${ }^{16}$.

Estas recomendaciones no fueron las únicas publicadas en ese momento, sino que hubo otras, no coincidentes, del Grupo de Trabajo de Bioética de la Sociedad Española de Medicina Intensiva, Crítica y Unidades Coronarias (SEMICYUC), bajo el título de «Recomendaciones éticas para la toma de decisiones en la situación excepcional de crisis por pandemia covid-19 en las unidades de cuidados intensivos» ${ }^{17}$, ante lo que el 23 de marzo la Dirección General de Políticas de Discapacidad del Ministerio de Derechos Sociales y Agenda 2030 pidió un informe al Comité de Bioética de España, que lo emitió el 25 de marzo $^{18}$, donde, en relación con algunas de las recomendaciones del Grupo de Trabajo de Bioética de SEMICYUC — así, la recomendación general n. ${ }^{\circ}$ 17: «En personas mayores se debe tener en cuenta la supervivencia libre de discapacidad por encima de la supervivencia aislada»; y la recomendación específica n. ${ }^{\circ}$ 4: "Cualquier paciente con deterioro cognitivo, por demencia u otras enfermedades degenerativas, no serían subsidiarios de ventilación mecánica invasiva» - señala que no son compatibles con la Convención Internacional sobre los Derechos de las Personas con Discapacidad, tratado firmado y ratificado por España. Añade el Comité que «sin duda, la edad, como otras circunstancias, pueden incidir en el pronóstico clínico, pero en ningún caso pueden obviarlo. Es necesario valorar las circunstancias concretas de cada paciente, sin excluir a nadie a priori. La única posible excepción de discriminación positiva por la edad son los niños $[\ldots] »^{19}$.

Posteriormente, la propia SEMICYUC, en el marco de un consenso entre veintiún sociedades científicas, seis institutos o cátedras de bioética o

16 Disponible en: https://bit.ly/2J7DBRz.

17 Disponible en: https://bit.ly/3kwSB9C. Puede verse un análisis crítico de algunas de estas recomendaciones y un comentario general en De Lora (2020); previamente, De Lora (2005: 9-32; 2009).

18 Disponible en: https://bit.ly/3e4vIle. Véase De Montalvo y Bellver (2020: 243-264).

19 De Montalvo (2020). 
cuidados paliativos y otras cinco entidades, postuló unas recomendaciones que van en la línea de las antes apuntadas por la $S E G G^{20}$.

Finalmente, el 2 de abril se publicó el Informe del Ministerio de Sanidad sobre los aspectos éticos en situaciones de pandemia: el SARS-CoV-2 $2^{21}$, en el que se asume el compromiso de que «las medidas que se adopten estarán presididas por los principios de equidad, no discriminación, solidaridad, justicia, proporcionalidad y transparencia, entre otros». Además,

la escasez de recursos, temporal o duradera, puede exigir el establecimiento de criterios de priorización de acceso a los mismos, lo que se hará con base en criterios objetivos, generalizables, transparentes, públicos y consensuados, sin perjuicio de valorar también los aspectos singulares e individuales que presente cada persona enferma por el virus.

Como criterios generales aplicables consideramos los siguientes:

1. ${ }^{\circ}$ No discriminación por ningún motivo ajeno a la situación clinica del paciente y a las expectativas objetivas de supervivencia, basadas en la evidencia.

2..$^{\circ}$ El principio de máximo beneficio en la recuperación de vidas humanas, que debe compatibilizarse con la continuación de la asistencia iniciada de forma individual de cada paciente.

3..$^{\circ}$ Gravedad del estado de enfermedad del paciente que evidencie la necesidad de cuidados intensivos (asistencia en unidades de cuidados intensivos y acceso a ventilación mecánica).

4. ${ }^{\circ}$ Expectativas objetivas de recuperación del paciente en el corto plazo a su estado previo de salud, teniendo en cuenta la concurrencia o no de patologías graves acompañantes que evidencien un pronóstico fatal (enfermos terminales con pronóstico de irreversibilidad, estado de coma irreversible, etc.), aunque pueda comportar una atención clínica añadida...

Debe subrayarse la absoluta proscripción de empleo de criterios fundados en la discriminación por cualquier motivo con la finalidad de priorizar pacientes en dichos contextos. En este sentido, excluir a pacientes del acceso a determinados recursos asistenciales o a determinados tratamientos, por ejemplo, por razón únicamente de una edad avanzada, resulta contrario, por discriminatorio, a los fundamentos mismos de nuestro estado de derecho (art. 14 de la Constitución española). En este sentido, los pacientes de mayor edad en caso de escasez extrema de recursos asistenciales deberán ser tratados en las mismas condiciones que el resto de la población, es decir, atendiendo a criterios clínicos de cada caso

20 Rubio et al. (2020).

21 Disponible en: https://bit.ly/3kaplnU. 
en particular Ello implica que, eventualmente y en la medida en que la escasez de medios básicos impida la cobertura de las necesidades de toda la población, se les aplicarán los criterios de admisión de pacientes con sintomas graves en unidades de cuidados intensivos y aplicación de ventilación mecánica asistida recogidos supra exactamente en las mismas condiciones que a cualquier otro ciudadano. Lo que no resulta en modo alguno aceptable es descartar ex ante el acceso a dichos medios a toda persona que supere una edad. Aceptar tal discriminación comportaría una minusvaloración de determinadas vidas humanas por la etapa vital en la que se encuentran esas personas, lo que contradice los fundamentos de nuestro Estado de Derecho, en particular el reconocimiento de la igual dignidad intrinseca de todo ser humano por el hecho de serlo (las cursivas son nuestras).

Concluimos, pues, que al menos en términos teóricos, la edad no ha sido durante la pandemia del COVID-19 un criterio excluyente para la protección de la salud como parte de la protección de la vida y la integridad física y moral (integridad personal). Y no podría serlo porque otra cosa supondría una vulneración de la Constitución y de la legislación sanitaria, pudiendo llevar aparejada, en su caso, la exigencia de responsabilidades de diverso tipo.

No obstante, en el momento de escribir estas líneas hay abiertas varias actuaciones parlamentarías y judiciales en las que, entre otras cosas, se está analizando si, efectivamente, ese mandato teórico ha tenido el debido correlato práctico. Por citar un caso particular, se ha aludido en los medios de comunicación a un protocolo interno dirigido a los profesionales de atención primaria, y fechado el 23 de marzo, según el cual la Consejería de Sanidad de la Comunidad de Madrid desaconsejaba el traslado a los hospitales de personas mayores de 80 años con estados graves de fragilidad desde sus domicilios ${ }^{22}$. De ser cierta la aplicación de este criterio se habría producido una discriminación

22 Disponible en: https://bit.ly/3jyNcgE, donde se puede consultar el documento original. En la misma información se dice: «Un portavoz de la Consejería de Sanidad madrileña aseguró el martes, a preguntas de EL PAÍS, que "el documento fue modificado" en una fecha posterior, que no precisó. En este segundo documento, según este portavoz, se eliminó la edad del paciente (más de 80 años) como uno de los criterios, que además quedaron reducidos a tres en lugar de cinco. También cambia la frase "se valorará su permanencia en domicilio" por "se valorará clínicamente y de forma individualizada la adecuación de su permanencia en domicilio”. Los tres criterios para los que se recomienda no derivar al hospital quedaron redactados posteriormente así: "Paciente con enfermedad de órgano terminal (insuficiencia cardiaca crónica avanzada, enfermedad obstructiva crónica grave, cirrosis hepática, insuficiencia renal crónica grave) y/o CFS mayor o igual que 5; paciente con escala clínica de fragilidad (CFS) de 8-9, paciente con cáncer en fase terminal"”.

En general, sobre la actividad de la Fiscalía en residencias de personas mayores y/o con discapacidad por la COVID-19, Pino et al. (2020a: 29). 
por razón de edad con consecuencias innegables en la integridad física y la propia vida de las personas afectadas.

Pero, con carácter más general, hay indicios para cuestionar que en muchas de las residencias de todo el país se prestara la atención adecuada a las personas necesitadas; así, y en el contexto ya constatado de insuficiencias previas a la pandemia, con ocasión de esta última se produjo

un déficit de protección de la salud de los trabajadores vinculado a las carencias de material y al cambio de especificaciones en los protocolos, siendo así que los trabajadores fueron, en la mayoría de los casos, uno de los principales vectores de contagio en las residencias [...] el elevado número de bajas entre los trabajadores de las residencias derivado de una pluralidad de motivos (contagios, temor, protocolos demasiado rigurosos o lo contrario $)^{23}$, [...] contribuyó a la sobrecarga del personal que permaneció en el puesto y a que estos trabajadores tuvieran que asumir algunas tareas para las que no estaban suficientemente preparados al no guardar relación con su desempeño habitual. En algunos casos se produjo la ausencia durante semanas de algunos perfiles profesionales imprescindibles para garantizar la atención cotidiana y, más grave, la atención sanitaria (Pino et al., 2020a: 17).

Habiendo pasado ya muchos meses después de la declaración del estado de alarma resulta, cuando menos, llamativo que no se hayan publicado datos oficiales por parte del Gobierno del número de personas fallecidas por COVID-19 o con síntomas similares en las residencias sociosanitarias -informaciones oficiosas hablan de 20600 muertos $^{24}$ — , con lo que no es fácil valorar la gestión llevada a cabo en cada una ni exigir, si estuviera justificado, las oportunas responsabilidades y, por último, sacar conclusiones que puedan servir de cara al futuro inmediato.

En relación con las responsabilidades, cabe recordar que la Ley Orgánica 4/1981, de 1 de junio, de los Estados de Alarma, Excepción y Sitio prevé (art. 3.2)

23 Según el informe de la Junta de Castilla y León El impacto del COVID-19 en las residencias de personas mayores de Castilla y León y medidas adoptadas, de 29 de septiembre de 2020, «el $15 \%$ de los trabajadores de centros de mayores han causado baja por COVID, y se alcanza el $21 \%$ si sumamos los que han estado en cuarentena por contacto con casos posibles o confirmados. Las dificultades para la contratación de personal sanitario y de atención directa siempre han sido frecuentes, pero durante la pandemia se han elevado. Las bajas fueron muy abundantes en marzo y abril. Las bajas con dificultades de sustitución alcanzan su máximo en los primeros días de abril para descender a la mitad una semana más tarde. En los centros con contagios, el $36 \%$ tuvo dificultades para sustituir el personal médico, el $57 \%$ el de enfermería, y el $64 \%$ el de atención directa».

24 Disponible en: https://bit.ly/3oxUvsY. 
que «quienes como consecuencia de la aplicación de los actos y disposiciones adoptadas durante la vigencia de estos estados sufran, de forma directa, o en su persona, derechos o bienes, daños o perjuicios por actos que no les sean imputables, tendrán derecho a ser indemnizados de acuerdo con lo dispuesto en las leyes». Este precepto, como se acaba de ver, remite a lo que contemplen otras disposiciones y no regula, como recuerda Doménech Pascual (2020: 102), la responsabilidad patrimonial de la Administración por los perjuicios que esta hubiera engendrado al omitir ciertas medidas de protección.

Además, habrá que tener en cuenta que, conforme a la Ley 40/2015, de 1 de octubre, de Régimen Jurídico del Sector Público, «los particulares tendrán derecho a ser indemnizados por las Administraciones Públicas correspondientes, de toda lesión que sufran en cualquiera de sus bienes y derechos, siempre que la lesión sea consecuencia del funcionamiento normal o anormal de los servicios públicos salvo en los casos de fuerza mayor o de daños que el particular tenga el deber jurídico de soportar de acuerdo con la Ley [...]» (art. 32.1). En este sentido, y como también señala Doménech Pascual (ibid.: 103 y 105),

los perjuicios provocados por esta pandemia seguramente eran inevitables hasta cierto punto, pero las Administraciones públicas españolas, con sus acciones y omisiones, han podido agravarlos y la exclusión de responsabilidad que implica la fuerza mayor no alcanza a los daños que se podían haber evitado o mitigado si hubieran tomado las debidas medidas de precaución [...].

El problema que puede plantearse en la práctica es el de precisar y probar si un determinado daño - v. gr., la muerte de cierta persona - era evitable o inevitable, es decir, el de identificar qué concretos perjuicios hubieran podido prevenirse si las Administraciones implicadas hubieran actuado diligentemente y cuáles se hubieran producido de todos modos, aun cuando su actuación no mereciera reproche alguno... [En todo caso] los daños sufridos por los ciudadanos con ocasión de la crisis del COVID-19 que las Administraciones hubieran podido prevenir adoptando ciertas medidas de precaución solo serán indemnizables si la omisión de estas puede considerarse culposa por suponer una infracción del deber de llevar el cuidado exigible ${ }^{25}$.

Habrá, pues, que ver en cada caso si los daños a la salud de concretas personas y las muertes causadas por la epidemia de COVID-19 pueden considerarse supuestos de fuerza mayor o si han sido originados por acciones $\mathrm{u}$ omisiones culposas bien de alguna entidad administrativa, de un particular que gestionaba servicios públicos, etc., tarea que, nos parece, se presenta con

25 Sobre la determinación del alcance de ese deber, Doménech Pascual (2019). 
no pocas complicaciones ${ }^{26}$, y que si se plantea en términos generales contra la inactividad de las entidades con competencias en la materia (Estado y comunidades autónomas), podría concluir en sentencias estimatorias pero de contenido meramente declarativo.

A este respecto, cabe mencionar la reciente STS 3024/2020, de 8 de octubre, de la Sección Cuarta de la Sala Tercera, que resolvió el recurso interpuesto por la Confederación Estatal de Sindicatos Médicos (CESM) contra la inactividad del Ministerio de Sanidad en lo referente al incumplimiento del art. 12.4 del Real Decreto 463/2020, de 14 de marzo, por el que se declara el estado de alarma para la gestión de la situación de crisis sanitaria ocasionada por el COVID-1927.

Pues bien, en dicha STS se dice:

En el comienzo del impacto de la pandemia, el Ministerio de Sanidad, aunque también el conjunto de Administraciones Públicas con responsabilidades en lo que el art. 44 de la Ley 14/1986, de 25 de abril, General de Sanidad, llama Sistema Nacional de Salud, que integran «el conjunto de los Servicios de Salud de la Administración del Estado y de los Servicios de Salud de las Comunidades Autónomas», no fue capaz de

26 Véase Medina Alcoz (2012).

27 Conforme a dicho artículo:

«1. Todas las autoridades civiles sanitarias de las administraciones públicas del territorio nacional, así como los demás funcionarios y trabajadores al servicio de las mismas, quedarán bajo las órdenes directas del Ministro de Sanidad en cuanto sea necesario para la protección de personas, bienes y lugares, pudiendo imponerles servicios extraordinarios por su duración o por su naturaleza.

2. Sin perjuicio de lo anterior, las administraciones públicas autonómicas y locales mantendrán la gestión, dentro de su ámbito de competencia, de los correspondientes servicios sanitarios, asegurando en todo momento su adecuado funcionamiento. El Ministro de Sanidad se reserva el ejercicio de cuantas facultades resulten necesarias para garantizar la cohesión y equidad en la prestación del referido servicio.

3. En especial, se asegurará la plena disposición de las autoridades civiles responsables del ámbito de salud pública, y de los empleados que presten servicio en el mismo.

4. Estas medidas también garantizarán la posibilidad de determinar la mejor distribución en el territorio de todos los medios técnicos y personales, de acuerdo con las necesidades que se pongan de manifiesto en la gestión de esta crisis sanitaria.

5. Las autoridades competentes delegadas ejercerán sus facultades a fin de asegurar que el personal y los centros y establecimientos sanitarios de carácter militar contribuyan a reforzar el Sistema Nacional de Salud en todo el territorio nacional.

6. Asimismo, el Ministro de Sanidad podrá ejercer aquellas facultades que resulten necesarias a estos efectos respecto de los centros, servicios y establecimientos sanitarios de titularidad privada». 
dotar a los profesionales de la salud de los medios precisos para afrontar protegidos la enfermedad y que así corrieron el peligro de contagiarse y de sufrir la enfermedad, como efectivamente se contagiaron muchos y entre ellos hubo numerosos fallecimientos.

Tal incapacidad no se corresponde con los fines perseguidos por el art. 12.4 del Real Decreto 463/2020, pues no cuesta esfuerzo establecer que no hubo una distribución de medios técnicos acorde con las necesidades puestas de manifiesto por la gestión de la crisis sanitaria. Cierto que las circunstancias fueron críticas y que la dimensión mundial de la pandemia pudo dificultar y retrasar el abastecimiento y su mejor distribución. Sin embargo, lo relevante para nuestro enjuiciamiento es que los medios disponibles no fueron los suficientes en los momentos iniciales para proteger debidamente al personal sanitario y, por tanto, la Sala así ha de reiterarlo ya que, insistimos, esa insuficiencia, no sólo la hemos apreciado ya sino que ha sido admitida por las partes y, además, no cuesta esfuerzo relacionarla con la elevada incidencia de la pandemia entre los profesionales sanitarios y, por tanto, en los derechos fundamentales de los que se vieron afectados.

Ahora bien, no nos corresponde en este proceso hacer un juicio de culpabilidad, ni imputaciones de responsabilidad, sino establecer si ha existido afectación de derechos fundamentales y tal extremo ya lo hemos constatado por lo que debemos acoger la primera de las pretensiones de la demanda y declararlo así, si bien con la precisión, ya explicada, de que la incapacidad se ha de predicar del Sistema Nacional de Salud en su conjunto y no sólo de la Administración General del Estado o del Ministerio de Sanidad aunque, dirigiéndose la demanda solamente contra el Ministerio de Sanidad, no podamos extender nuestro pronunciamiento más allá (FJ 7).

En conclusión, la Sala acuerda:

Estimar en parte el recurso contencioso-administrativo n. ${ }^{\circ}$ 91/2020, interpuesto por la Confederación Estatal de Sindicatos Médicos contra la inactividad del Ministerio de Sanidad y declarar, en los términos del fundamento séptimo, que los profesionales sanitarios carecieron de los medios de protección necesarios lo cual supuso un serio riesgo para los derechos fundamentales que les reconoce el art. 15 en relación con los arts. 43.1 y 40.2 de la Constitución.

\section{LOS LÍMITES A LA LIBERTAD DE CIRCULACIÓN DE LAS PERSONAS MAYORES DURANTE LA VIGENCIA DEL ESTADO DE ALARMA POR COVID-19}

Como es conocido, las restricciones a la libertad de circulación impuestas por la declaración del estado de alarma se concretaron en el art. 7 del Real 
Decreto 463/2020, de 14 de marzo, titulado, precisamente, «Limitación de la libertad de circulación de las personas», y que en su punto 1 dispone:

Durante la vigencia del estado de alarma las personas únicamente podrán circular por las vías o espacios de uso público para la realización de las siguientes actividades, que deberán realizarse individualmente, salvo que se acompañe a personas con discapacidad, menores, mayores, o por otra causa justificada: a) Adquisición de alimentos, productos farmacéuticos y de primera necesidad. b) Asistencia a centros, servicios y establecimientos sanitarios. c) Desplazamiento al lugar de trabajo para efectuar su prestación laboral, profesional o empresarial. d) Retorno al lugar de residencia habitual. e) Asistencia y cuidado a mayores, menores, dependientes, personas con discapacidad o personas especialmente vulnerables. f) Desplazamiento a entidades financieras y de seguros. g) Por causa de fuerza mayor o situación de necesidad. h) Cualquier otra actividad de análoga naturaleza $[\ldots]^{28}$.

\section{EL CONFINAMIENTO GENERALIZADO DE LAS PERSONAS MAYORES HASTA EL 2 DE MAYO DE 2020 Y SU ESPECIAL INCIDENCIA EN QUIENES VIVÍAN EN RESIDENCIAS SOCIOSANITARIAS}

De la lectura del citado art. 7 se deduce con claridad que la limitación de la circulación obliga a todas las personas y, por lo que respecta a las mayores, únicamente se contempló en el Decreto original que su asistencia y cuidado fuese una de las circunstancias que justificaba «circular por las vías o espacios de uso público». El 17 de marzo se publicó una reforma para permitir, además de las salidas individuales a los efectos previstos, "que se acompañe a personas con discapacidad, menores, mayores». Y por medio de la Instrucción de 19 de marzo de 2020, del Ministerio de Sanidad, se acordó, como explica su preámbulo, «con el objeto de proteger a los colectivos más vulnerables», habilitar, en el apartado segundo, "a las personas con discapacidad, que tengan alteraciones conductuales, como por ejemplo personas con diagnóstico de espectro autista y conductas disruptivas, el cual se vea agravado por la situación de confinamiento derivada de la declaración del estado de alarma, y a un acompañante, a circular por las vías de uso público, siempre y cuando se respeten las medidas necesarias para evitar el contagio».

Pero, como regla general, se mantuvo la prohibición de «circular por las vías o espacios de uso público» a las personas mayores durante un mes y medio; concretamente, desde el 14 de marzo, fecha en la que se decretó el estado de alarma, hasta la entrada en vigor, el día 2 de mayo, de la Orden

28 Cotino Hueso (2020). 
SND/380/2020, de 30 de abril, sobre las condiciones en las que se puede realizar actividad física no profesional al aire libre durante la situación de crisis sanitaria ocasionada por el COVID-19, en cuyo preámbulo se explica:

La práctica de actividad física y la reducción del sedentarismo son factores que tienen una influencia positiva en la mejora de la salud de las personas, en la prevención de las enfermedades crónicas y, por tanto, en la calidad y la esperanza de vida de la población. Así, la actividad física practicada con regularidad tiene múltiples beneficios, como, por ejemplo, la mejora del bienestar emocional, de la función inmunitaria, la reducción del riesgo de desarrollar ciertas enfermedades como diabetes tipo 2, enfermedades cardiovasculares y en general una mejora de la condición física. Asimismo, la práctica de actividad fisica al aire libre conlleva beneficios adicionales, como la exposición a la luz natural para la sintesis de vitamina D o beneficios sobre la salud mental.

Además de estos beneficios, para la población adulta mayor, la actividad fisica es también un factor clave para mantener una adecuada funcionalidad, un menor riesgo de caidas, unas funciones cognitivas mejor conservadas, y para prevenir posibles limitaciones funcionales moderadas y graves.

A su vez, permitir salidas para la práctica de actividad física es una medida de equidad, ya que las condiciones de las viviendas y los estilos de vida no son iguales en todos los hogares, por lo que la declaración del estado de alarma supone un impacto desigual en la población, afectando especialmente a aquellos hogares que viven en condiciones de vida de mayor vulnerabilidad [...].

Teniendo en cuenta los beneficios asociados a la práctica de una actividad fisica, unidos a los efectos negativos asociados al sedentarismo derivado de la propia declaración del estado de alarma, se considera que existe una situación de necesidad que ampara, con arreglo a lo previsto en el art. 7.1.g) del Real Decreto 463/2020, de 14 de marzo, y en línea con la finalidad de su art. 7.2, la posibilidad de que las personas de 14 años en adelante retomen la actividad física al aire libre, siempre que para ello se adopten las oportunas medidas de seguridad. Del mismo modo, las actividades permitidas por esta orden resultan necesarias para el bienestar fisico y psíquico de la población, entendiéndose, por tanto, que se trata de una actividad de análoga naturaleza, de acuerdo con lo previsto en el art. 7.1.h), a la asistencia y cuidado a determinados colectivos prevista en el párrafo e) de este mismo art. [...] (las cursivas son nuestras).

A partir de la entrada en vigor de esta orden, y de acuerdo con su art. 5.1.b), «[...] las personas mayores de 70 de años podrán practicar deporte individual y pasear entre las 10:00 horas y las 12:00 horas y entre las 19:00 horas y las 20:00 horas. Las personas mayores de 70 años podrán salir acompañadas de una persona conviviente de entre 14 y 70 años». 
No obstante, una semana antes se había publicado la Orden $\mathrm{SND} / 370 / 2020$, de 25 de abril, sobre las condiciones en las que deben desarrollarse los desplazamientos por parte de la población infantil durante la situación de crisis sanitaria ocasionada por el COVID-19, que entró en vigor el 26 de abril. Según su preámbulo,

y con el objeto de proteger a la población infantil, se hace preciso dictar una orden para establecer el modo en que los niños y niñas pueden realizar desplazamientos fuera de su domicilio, con el fin de aliviar las medidas a las que han estado sometidos, y las posibles consecuencias negativas que ello conlleva, al tiempo que se respetan las medidas de seguridad necesarias.

En este sentido, el Comité de los Derechos del Niño de las Naciones Unidas ha realizado recientemente un llamamiento general a los Estados alertando sobre los efectos físicos, psicológicos y emocionales en la infancia a consecuencia de la epidemia ocasionada por el COVID-19, de las medidas adoptadas y sus consecuencias. Asimismo, el citado Comité considera que, en la situación de emergencia sanitaria, se debería permitir a los niños y niñas poder disfrutar diariamente de actividades fuera de casa de manera supervisada y manteniendo las garantías de higiene y distanciamiento social.

El impacto de la emergencia sanitaria en niños y niñas ha alterado su rutina de vida en todos sus ámbitos, como son el familiar, social, o educativo, entre otros. Del mismo modo, este impacto puede conllevar aspectos negativos en su salud somática (mayor tendencia al sobrepeso y obesidad, hipotonía, incremento del sedentarismo, etc.), así como en su salud emocional (irritabilidad, apatía y decaimiento, alteraciones del sueño, incremento de la dependencia de la persona adulta, etc.).

Teniendo en cuenta dichos efectos negativos, los cuales han evolucionado a medida que lo ha hecho la crisis sanitaria, se considera que existe una situación de necesidad que ampara... la posibilidad de que la población infantil efectúe determinados desplazamientos, siempre que para ello se adopten las oportunas medidas de seguridad. Del mismo modo, los desplazamientos permitidos por esta orden resultan necesarios para el bienestar físico y psíquico de las personas menores de edad [...].

Cabe preguntarse si no habría sido adecuada una orden similar para permitir los desplazamientos de las personas mayores, que a esa fecha llevaban confinadas, como el resto de la población, 43 días; al menos de población mayor especialmente vulnerable y, como es obvio, con las adecuadas medidas de seguridad, pues aunque de un modo diferente a la población infantil, sobre esas personas también estaban haciendo mella física y psicológica tantos días sin poder salir a pasear. 
Hay que recordar, además, que según el informe del Observatorio Social de La Caixa Envejecer en España ${ }^{29}$, hay en nuestro país más de 430000 personas mayores de 65 años que no tienen agua corriente, 350000 carecen de sistema de alcantarillado y a casi 3500000 no les es posible mantener su casa a una temperatura adecuada. En suma, con datos de 2018, el 20,1\% de las personas mayores de 65 años de España (1596675) sufren vulnerabilidad residencial extrema, definida por la acumulación de problemas graves en la vivienda, y dicha vulnerabilidad se ve notablemente incrementada cuando se está obligado a permanecen esas viviendas la práctica totalidad del día.

Asimismo, hay que recordar algunos datos que se apuntaban al principio de este texto y que aparecen en el mencionado informe de Pérez et al. (2020): por una parte, la prohibición general de llevar a cabo paseos durante mes y medio puede agravar algunas patologías muy presentes entre las personas mayores y, de manera singular, las enfermedades circulatorias, que son la causa más frecuente de asistencia hospitalaria para ese grupo de población (19,8\%) y la principal causa de muerte; como también se dijo, un 22,2\% de personas mayores tiene obesidad, y otro $41,5 \%$ sobrepeso.

En segundo lugar, es conocido que un aislamiento prolongado conlleva asimismo consecuencias en la salud psíquica de todas las personas y algunas circunstancias presentes entre la población mayor hacen que este colectivo pueda verse afectado de forma especial: el citado informe constata que durante la vejez, y hasta edades muy avanzadas, la edad aumenta la probabilidad de vivir en soledad y ese aislamiento se complica por la existencia de una brecha digital entre los mayores y el resto de la población, que si bien se ha reducido en los últimos años, sigue siendo relevante: la brecha entre el grupo de edad más conectado (16-24 años) y el de los mayores (65-74 años) era en 2019 de a 35,5 puntos.

Por si fuera poco, no hay que dejar de tener presente que es, precisamente, la población mayor la que más ha visto peligrar su salud y su vida como consecuencia de la pandemia, lo que implica estrés y ansiedad adicionales, que pueden desembocar en estados de agotamiento y en el propio agravamiento de patologías previas ${ }^{30}$.

29 Disponible en: https://bit.ly/2JMoQ7d.

30 En un documento de 18 de marzo (Mental health and psychosocial considerations during the COVID-19 outbreak) la Organización Mundial de la Salud advertía: «Older adults, especially in isolation and those with cognitive decline/dementia, may become more anxious, angry, stressed, agitated and withdrawn during the outbreak or while in quarantine [...]» (disponible en: https://bit.ly/3l9kQv4. Véase al respecto, por ejemplo, Wang et al. (2020). Con una dimensión divulgativa, Giménez Rodríguez (2020). 


\section{LOS LÍMITES ADICIONALES A LAS PERSONAS MAYORES RESIDENTES EN CENTROS SOCIOSANITARIOS: PROHIBICIÓN DE SALIR DE LOS CENTROS Y DE RECIBIR VISITAS}

En el varias veces mencionado informe de Pérez et al. (2020) se dice que «en España hay 4,1 plazas de residencia por cada 100 personas mayores; en total, 372985 plazas en 2019. Se desconoce el nivel de ocupación, pero puede situarse entre el 75-80\%». Si damos por buenos o aceptables ambos datos, estaríamos hablando de entre 280000 y casi 300000 personas residentes a las que el confinamiento decretado para contener la propagación de la pandemia les obligó a permanecer en los centros sin recibir visitas ni poder salir a la calle hasta, en no pocos casos, el final del estado de alarma. Y, lo que no es baladí, en unos centros, que en general, y según el Defensor del Pueblo (2020), padecían importantes deficiencias:

Es necesario un número suficiente de personal para prestar servicios en los centros residenciales. Por tanto, se requiere una profunda revisión al alza de las ratios de personal de atención directa para mejorar la calidad asistencial, pues se han quedado manifiestamente desfasadas [...].

Resulta importante mejorar la cualificación del personal que presta sus servicios en el sistema residencial [...] un modelo de residencias propiamente sociosanitario, con atención médica y de enfermería más amplia y extensa, en España no está regulado ni ha sido así organizado de forma general para todo el sistema. Sería útil estudiar su viabilidad y conveniencia [...].

Es imprescindible que las comunidades autónomas creen con urgencia, o en su caso incrementen adecuadamente, unos servicios de inspección suficientemente dotados de personal correctamente formado, para que puedan llevar a cabo su función de vigilancia de forma eficaz, para que los centros mantengan los requisitos normativos exigidos para su correcto funcionamiento y unos niveles adecuados de calidad en la prestación del servicio de atención residencial de mayores [...].

En definitiva, resultan necesarias reformas normativas de calado que garantice a los mayores el ejercicio de una serie de derechos y que se preste una mayor atención presupuestaria, formativa, dotacional e inspectora en los centros residenciales que permita hacer frente a toda una serie de retos que hoy tiene planteado este sector, y que con toda seguridad se incrementara en un futuro inmediato.

Pues bien, conocido el contexto, hay que recordar que la Orden SND/399/2020, de 9 de mayo, para la flexibilización de determinadas restricciones de ámbito nacional, dispuso (art. 2) que «las personas vulnerables al COVID-19 también podrán hacer uso de las habilitaciones previstas en esta 
orden, siempre que su condición clínica esté controlada y lo permita, y manteniendo rigurosas medidas de protección», es decir, se permitía la salida a la calle en las franjas horarias habilitadas (en el caso de las personas mayores de 70 años de 10 a 12 y de 19 a 20).

Sin embargo, se mantuvo hasta el 25 de mayo de 2020 una prohibición que ofrece serios reparos constitucionales: la ya citada Orden SND/380/2020, de 30 de abril, sobre las condiciones en las que se puede realizar actividad física no profesional al aire libre durante la situación de crisis sanitaria ocasionada por el COVID-19, que, en su preámbulo, como ya hemos visto, insiste, entre otras cosas, en que "para la población adulta mayor la actividad física es también un factor clave para mantener una adecuada funcionalidad, un menor riesgo de caídas, unas funciones cognitivas mejor conservadas, y para prevenir posibles limitaciones funcionales moderadas y graves».

A pesar de estas consideraciones, y sin mayor fundamentación, se dice poco después que, «no obstante los beneficios señalados, en el momento actual de la crisis sanitaria, y con el fin de proteger uno de los colectivos más vulnerables, en esta fase no se contempla la práctica de la actividad física prevista en esta orden por parte de los residentes en los centros sociosanitarios de mayores" (las cursivas son mías).

En el mismo sentido, en el art. 2 se dispone (apdo. 1) que «se habilita a las personas de 14 años en adelante, a circular por las vías o espacios de uso público para la práctica de las actividades físicas permitidas por esta orden [...]», pero más adelante (apdo. 5) se prevé que «no podrán hacer uso de la habilitación contenida en el apartado 1 las personas que presenten síntomas o estén en aislamiento domiciliario debido a un diagnóstico por COVID-19, o que se encuentren en período de cuarentena domiciliaria por haber tenido contacto con alguna persona con síntomas o diagnosticado de COVID-19. Asimismo, tampoco podrán hacer uso de dicha habilitación los residentes en centros sociosanitarios de mayores» (las cursivas son mías).

En suma, se les aplicó a todas las personas residentes en centros sociosanitarios (tuvieran o no diagnosticado COVID-19, presentaran o no síntomas y estuvieran o no en cuarentena) el mismo régimen que a las personas a las que pareció proporcional limitar su actividad física por encontrarse en una situación de riesgo: la prohibición de disfrutar de un tiempo de actividad física.

Esta prohibición absoluta parece, cuando menos, desproporcionada: como se explica en la misma Orden, la actividad física es especialmente recomendable para las personas mayores en aras a «mantener una adecuada funcionalidad, un menor riesgo de caídas, unas funciones cognitivas mejor conservadas, y para prevenir posibles limitaciones funcionales moderadas y graves». ¿Por qué no se pudieron beneficiar de esta actividad, importante para 
su salud física y psíquica, ninguna de las personas que vivían en centros sociosanitarios? No se olvide que estamos, por si hubiera alguna duda, hablando del ejercicio del derecho fundamental a la libertad de circulación y también del derecho a la protección de su salud. Se dice, no obstante, con un claro resabio paternalista, que la prohibición se adoptó para "proteger uno de los colectivos más vulnerables». ¿Se protegió contra de su voluntad a personas autónomas y con capacidad de decidir? ¿Y se tomó, sin matiz o excepción alguna, una medida general e indiscriminada? ¿No hubieran podido hacer esa actividad ni siquiera en las inmediaciones del centro y/o acompañados de familiares, cuidadores o voluntarios en una concreta franja horaria?

Pues bien, y como ya se ha dicho más arriba, la propia Ley 33/2011, de 4 de octubre, General de Salud Pública prevé que «todas las personas tienen derecho a que las actuaciones de salud pública se realicen en condiciones de igualdad sin que pueda producirse discriminación por razón de nacimiento, origen racial o étnico, sexo, religión, convicción u opinión, edad, discapacidad, orientación o identidad sexual, enfermedad o cualquier otra condición o circunstancia personal o social $[\ldots] »$.

Aquí nos encontramos con una aparente discriminación, pues la medida se adoptó de manera indiferenciada para todas las personas residentes, al margen de si su salida a la calle suponía algún tipo de riesgo para las demás personas que vivían en el centro sociosanitario o que trabajaban en él, y todo ello sin ofrecer criterio alguno objetivo y razonable para tal exclusión.

Dos meses después de la declaración del estado de alarma se aprobó la "Orden SND/414/2020, de 16 de mayo, para la flexibilización de determinadas restricciones de ámbito nacional establecidas tras la declaración del estado de alarma en aplicación de la fase 2 del Plan para la transición hacia una nueva normalidad», en cuyo art. 20 se regulan las «visitas a viviendas tuteladas, centros residenciales de personas con discapacidad y centros residenciales de personas mayores». Ahí se dispuso:

1. Las comunidades autónomas y las ciudades autónomas podrán permitir en su ámbito territorial la realización de visitas a los residentes de viviendas tuteladas, centros residenciales de personas con discapacidad y centros residenciales de personas mayores. En este último caso, estas visitas se realizarán preferentemente en supuestos excepcionales, tales como el final de la vida o el alivio de descompensación neurocognitiva del residente.

Además, las visitas se sujetan a un protocolo estricto (cita previa, un visitante por residente, uso de equipos de protección adecuados...) y quedan excluidas en todo caso las visitas a los «centros residenciales de personas mayores en los que haya casos confirmados de COVID-19, o en los que algún residente se encuentre en período de cuarentena por haber tenido contacto estrecho con alguna persona con síntomas o diagnosticada de COVID-19 (las cursivas son nuestras). 
La Orden de 16 de mayo fue modificada, en lo que aquí nos interesa, por el art. 5.2 de la Orden SND/440/2020, de 23 de mayo, en vigor desde las 00:00 horas del día 25 de mayo de 2020, y en el que se trasladó a las comunidades autónomas y las ciudades autónomas la fijación de los requisitos y condiciones para "la realización de visitas a los residentes de viviendas tuteladas, centros residenciales de personas con discapacidad y centros residenciales de personas mayores, así como la realización de paseos por los residentes", con lo que desde esa fecha ya no era el Ministerio de Sanidad el responsable último de dichas condiciones.

Y lo que ocurrió desde entonces y hasta el final de la vigencia del estado de alarma muestra unas diferencias muy significativas entre unas comunidades y otras si nos atenemos a las normas e indicaciones, no fáciles de encontrar en algunos casos, emitidas por las autoridades autonómicas y ello al margen de que no todos los territorios estuviesen en la misma fase, pues han coexistido también reglas distintas entre comunidades en situación sanitaria similar.

A modo de resumen, ha habido, en primer lugar, tres comunidades (Andalucía, Aragón, Galicia) que han abierto las residencias de mayores durante la fase II a las visitas, con un protocolo estricto, y que también han regulado los paseos en esa misma fase.

- En Andalucía desde la entrada en vigor de la Orden de 28 de mayo «se reanudan las visitas y los paseos en los centros residenciales de personas mayores» y se establecen las «condiciones mínimas para la realización de paseos de las personas usuarias de los centros residenciales de personas mayores [...] el residente podrá salir a dar paseos solo o ir acompañado de su cuidador habitual, ya sea familiar o no, en función de su grado de autonomía, debiendo cumplir con las mismas medidas de protección» ${ }^{31}$.

- En Aragón se aprobó la Orden CDS/406/2020, de 25 de mayo, según la cual «se permiten las visitas en los centros de servicios sociales especializados de carácter residencial, que no presenten casos confirmados, y siempre y cuando se respeten los requisitos mínimos para evitar el contagio [...]». Por lo que se refiere a los paseos, «las personas residentes asintomáticas, en centros de servicios sociales especializados de atención a personas mayores, que no presenten casos confirmados, podrán circular por las vías públicas o espacios de uso público [...]. La circulación queda

31 Por medio de la Orden de 6 de junio de 2020 se modifica la Orden de 4 de junio y se acuerda «la prórroga de las medidas adoptadas en virtud de la Orden de 28 de mayo de 2020». La prórroga se extiende hasta la finalización del estado de alarma: las 00:00 horas del día 21 de junio de 2020. 
limitada a la realización de un paseo diario, de un máximo de 60 minutos de duración y a una distancia no superior de un kilómetro con respecto al domicilio de la residencia».

- En Galicia se aprobó el «Plan de reactivación no ámbito sociosanitario en relación con la infección polo virus SARS-CoV-2» de la Consellería de Sanidade según el cual: «Etapa I: Poderán realizarse paseos en zonas amplas ao aire libre nunha distancia dun quilómetro ao redor do centro ou en espazos verdes do propio centro, mantendo sempre as medidas de distanciamento e utilizando máscara. Permitirase unha visita á semana pola persoa de referencia con cita previa. Etapa II: As persoas válidas poderán realizar saídas á farmacia e ao banco á primeira hora da mañá evitando aglomeracións de persoas neles [...]. Permitiranse dúas visita á semana pola persoa de referencia con cita previa. Etapa III: Poderán realizar saídas ao entorno urbano evitando lugares onde se concentren moitas persoas $[\ldots] »$.

En segundo lugar, otras comunidades (Asturias, Castilla-La Mancha, Murcia, País Vasco) han descartado como regla las visitas y los paseos en la fase II, e incluso en la Fase III, de manera que la mayoría de las personas residentes en estos centros han permanecido sin visitas ni paseos durante toda la vigencia del estado de alarma, desde el 14 de marzo hasta el 20 de junio (98 días).

- Así, en Asturias se aprobó la Resolución de 27 de mayo de 2020, de la Consejería de Derechos Sociales y Bienestar, por la que se establecen los requisitos y condiciones para la realización de visitas en centros residenciales para personas mayores, así como la realización de paseos, con vigencia prevista «hasta la finalización de la declaración del período del estado de alarma o prórrogas del mismo». Las visitas se realizarán únicamente en «supuestos excepcionales, tales como el final de la vida o el alivio de descompensación neurocognitiva del residente y «los paseos comenzarán en una fase posterior de desescalada o en el momento a partir que lo determine la autoridad sanitaria».

- En Castilla-La Mancha la normativa está incluida en la Resolución de 27/05/2020, de la Consejería de Sanidad, que mantiene «la restricción total de visitas a las viviendas y a los centros residenciales para personas mayores, que no tengan relación profesional con el centro o sean estrictamente necesarias». Los paseos o salidas de las personas residentes ni se mencionan.

- En el País Vasco el régimen podía variar de una provincia a otra pero, en principio, las visitas solo se admitieron a partir de la fase III. 
- Finalmente, la Región de Murcia tuvo a gala un régimen muy estricto de desconfinamiento, manteniendo la restricción de las visitas de familiares y sin contemplar los paseos fuera de las residencias.

En tercer lugar, la mayoría de las comunidades (Canarias, Cantabria, Castilla-León, Cataluña, Extremadura, Illes Balears, Madrid, Navarra, La Rioja, Comunidad Valenciana) han previsto, durante la fase II, y con restricciones, las visitas, pero no, con carácter general, los paseos.

- En Canarias se aprobó la Orden conjunta de 29 de mayo de 2020. Por lo que se refiere a las visitas, «se asegurará como máximo una visita semanal de duración no superior a una hora, que podrá ser, esta última, ampliable según las características de cada centro». En relación con los paseos, «no está permitida la salida de las personas residentes a cualquier vía o espacio de uso público, salvo en el caso de paseos terapéuticos de personas con discapacidad, trastornos del espectro autista o con casuísticas de salud mental. Con esta salvedad, las salidas al exterior de los centros y demás establecimientos residenciales solo están permitidas, por motivos terapéuticos, para el caso de personas que no puedan soportar confinamientos indefinidos, siempre y cuando se realice acompañadas, se utilicen las medidas de protección adecuadas y se evite el contacto y la interacción con otras personas».

- En Cantabria la norma aplicable ha sido la Resolución de 26 de mayo de acuerdo con la cual «no está permitida la salida de las personas residentes a cualquier vía o espacio de uso público, salvo en el caso que, debido a la ubicación del centro residencial, el Ayuntamiento correspondiente haya establecido un perímetro de seguridad alrededor del mismo. Con esta salvedad, las salidas al exterior de los centros solo están permitidas por motivos terapéuticos para el caso de personas que no puedan soportar confinamientos indefinidos siempre y cuando se realice acompañados por un profesional, se utilicen las medidas de protección adecuadas y se evite el contacto y la interacción con otras personas». "La dirección del centro organizará las visitas que se efectuarán siempre con cita previa, por un tiempo limitado y un familiar por residente (a ser posible siempre la misma persona) y evitando el contacto físico. Se asegurará al menos una visita semanal».

- En Castilla y León se elaboró un plan de desescalada en las residencias según el cual, «sin perjuicio de las visitas a los usuarios de los centros residenciales que se realicen por razones excepcionales, tales como el final de la vida o el alivio de descompensación neurocognitiva del residente que podrán realizarse en cualquier etapa, una vez iniciada la fase 2 , para 
las visitas a los residentes se tendrán en cuenta las siguientes consideraciones: se deberá concertar previamente la visita con el centro residencial [...]. Se limitará a un máximo de 1 visita de 1 sola persona al día por residente, de acuerdo a lo que disponga cada centro. El número de visitantes podrá ampliarse a dos cuando uno de los visitantes requiera de la ayuda de una tercera persona. La duración aproximada de cada visita se estima de 30-45 minutos de duración, según la capacidad organizativa de cada centro».

- En Cataluña también se aprobó en mayo un plan de desescalada con los siguientes itinerarios: «Fase 0: quan el suport i procés d'atenció a les persones ho aconsellin es facilitaran en situació de seguretat les visites d'acompanyament i suport al final de vida. Fase I: afegir la priorització de les visites de residents en situació de descompensació de malaltia crònica. Fase II: generalització de visites a tot tipus de residents. Màxim d'una persona per resident, amb cita prèvia i amb les especificacions que es marquen en aquest document. Fase III: visites de familiars (fins a 3 persones) en zones exteriors del centre residencial».

- En Extremadura la normativa ha estado incluida en la Resolución de 25 de mayo de 2020, del vicepresidente segundo y consejero, donde se dispuso que «se permitirá la realización de visitas de familiares en aquellos centros que se encuentren libre de COVID-19 y en donde ningún residente se encuentre en cuarentena, observando siempre las siguientes condiciones: se permitirá la visita de un solo familiar por residente y una vez por semana. No podrán acceder los familiares que presenten síntomas compatibles con la infección de coronavirus. Las visitas serán autorizadas por la dirección del centro, previa petición por el familiar, fijándose el día, la hora y el tiempo de duración de la visita [...]».

- En Illes Balears la norma de referencia ha sido la Resolución de la consejera de Asuntos Sociales y Deportes de 25 de mayo de 2020 de acuerdo con la cual «las visitas se tienen que acordar previamente con el centro mediante un sistema de cita previa».

- En la Comunidad de Madrid, y de conformidad con el Plan de Transición hacia una Nueva Normalidad de 22 de mayo de 2020, durante la fase II se produjo el restablecimiento de las visitas de familiares semanales (1 por residente) para aquellos residentes que tengan PCR negativo de COVID-19 en espacios designados en anterior fase, con las medidas de seguridad e higiene determinadas por las autoridades sanitarias. Estas visitas se debían realizar mediante cita previa.

- La Comunidad Foral de Navarra aprobó la Orden Foral 161/2020, de 25 de mayo, de la Consejera de Derechos Sociales. Con arreglo a la misma solo se permitieron las visitas a centros residenciales de personas 
mayores en supuestos excepcionales, tales como el final de vida, el alivio de descompensación neurocognitiva del o de la residente o en aquellas situaciones de grave deterioro de la situación psicoafectiva del o de la residente. Posteriormente, se aprobó la Orden Foral 202/2020, de 15 de junio, y desde este momento se autorizaron las visitas en los términos y condiciones señaladas en la Orden Foral 161/2020. Igualmente se autorizó la salida de las personas libres de enfermedad COVID-19 y que no estuvieran en cuarentena por contacto estrecho.

- En La Rioja se elaboró un protocolo redactado por la Dirección General de Dependencia, Discapacidad y Mayores para regular las visitas de familiares a residentes en viviendas especializadas y residencias de personas mayores y de personas con discapacidad, permitidas desde el día 28 de mayo. Todas las visitas se ajustarían a una duración máxima de treinta minutos siendo las residencias las encargadas de gestionarlas previa solicitud. Hasta la fase 3 no se permitió realizar paseos por el exterior.

- Finalmente, en la Comunidad Valenciana se aprobó la Resolución de 29 de mayo de 2020, de la Vicepresidencia y Conselleria de Igualdad y Políticas Inclusivas. Conforme a esta norma, el régimen ha sido el siguiente: «Fase I: Visites en cas de força major. A fi de garantir un procés final de la vida digne a les persones majors i contribuir al desenvolupament d'un duel menys traumàtic per al seu entorn, es permetran de manera excepcional per part de la direcció del centre residencial les visites de familiars o persones reunides de referencia garantint així un tracte humanitzat i d'afectes. Així mateix, es permetran aquestes visites per a l'alleujament de la descompensació neurocognitiva de la persona resident quan així ho considere l'equip tècnic professional del centre. La visita s'autoritzarà per a un màxim de dues persones per persona resident. Es realitzarà amb les degudes mesures de seguretat i higiene, de manera individual, excepte en el cas de persones convivents, que hi podran entrar conjuntament. Fase II: Es permetran les visites, sempre amb cita prèvia, de fins a dos familiars o persones reunides per persona resident, que hi hauran d'entrar de manera individual, excepte si són convivents, i en aquest cas hi podran entrar juntes. Fase III: A més de les eixides per força major, es permetran les eixides d'esplai individuals i grupals d'acord amb el pla de contingència».

\section{A MODO DE BREVE CONCLUSIÓN}

De lo visto hasta aquí podemos concluir que, al menos en términos teóricos, durante la pandemia de la COVID-19 la condición de persona 
mayor no ha sido un criterio excluyente para la protección de la salud como parte de la protección de la vida y la integridad física y moral.

No obstante, y como ya se ha dicho, en el momento de finalizar estas líneas siguen abiertas varias actuaciones parlamentarías y judiciales en las que, entre otras cosas, se está analizando si, efectivamente, ese mandato teórico ha tenido el debido correlato práctico en el ámbito de las residencias sociosanitarias. $Y$ es que hay indicios para cuestionar que en muchas de las residencias de todo el país se prestara la atención adecuada a las personas necesitadas, pues a las constatadas insuficiencias previas a la pandemia, con ocasión de esta última se produjo un déficit de protección de la salud de los trabajadores vinculado a las carencias de material y al cambio de especificaciones en los protocolos, siendo así que los trabajadores fueron, en la mayoría de los casos, uno de los principales vectores de contagio en las residencias. En algunas residencias se produjo la ausencia durante semanas de algunos perfiles profesionales imprescindibles para garantizar la atención cotidiana y, lo que es más grave, la atención sanitaria

Meses después de la declaración del estado de alarma es criticable que no se hayan publicado datos oficiales del número de personas fallecidas por COVID-19 o con síntomas similares en las residencias sociosanitarias -informaciones oficiosas hablan de 20600 muertos-, con lo que no es fácil valorar la gestión llevada a cabo en cada una. Habrá que exigir, si estuviera justificado, las oportunas responsabilidades y, por último, sacar conclusiones que puedan servir de cara al futuro inmediato.

Por lo que respecta a la libertad deambulatoria de las personas mayores y su correlación con su salud física y psíquica, no se ha tenido suficientemente en cuenta la necesidad de garantizarles, en particular a las que más lo necesitaban, unas salidas y paseos terapéuticos adoptando, como es obvio, las adecuadas medidas de seguridad, pues, aunque de un modo diferente a la población infantil, sobre esas personas también ha hecho mucha mella física y psicológica un confinamiento tan estricto y prolongado.

En esa línea crítica hay que recordar, por lo que respecta a quienes han pasado la crisis sanitaria en centros residenciales, públicos y privados, tuvieran o no diagnosticado COVID-19, presentasen o no síntomas y estuvieran o no en cuarentena, que se les ha aplicado un mismo régimen restrictivo: la prohibición de disfrutar de un tiempo de actividad física y de recibir visitas, limitaciones que parecen, cuando menos, desproporcionadas, pues se han impuesto de manera indiferenciada para todas las personas residentes, al margen de si su salida a la calle suponía algún tipo de riesgo especial para las demás personas que vivían en el centro sociosanitario o que trabajaban en él.

No está de más, para finalizar, emplear unas palabras del Defensor del Pueblo: «Resultan necesarias reformas normativas de calado que garanticen 
a los mayores el ejercicio de una serie de derechos y que se preste una mayor atención presupuestaria, formativa, dotacional e inspectora en los centros residenciales que permita hacer frente a toda una serie de retos que hoy tiene planteado este sector, y que con toda seguridad se incrementara en un futuro inmediato».

\section{Bibliografía}

Barranco Avilés, M. C. (2014). Derechos humanos y vulnerabilidad. Los ejemplos del sexismo y el edadismo. En M. C. Barranco Avilés, C. Churruca Muguruza (eds.). Vulnerabilidad y protección de los derechos humanos (pp. 17-44). Valencia: Tirant lo Blanch.

Cardona, B., Flores, F. y Cabeza, J. (2019). Edad, discriminación y derechos. Cizur Menor: Aranzadi-Thomson Reuters.

Cebada Romero, A. (2019). Las personas de edad en el Derecho Internacional: hacia una convención de la ONU sobre los derechos de las personas de edad. En B. Cardona, F. Flores y J. Cabeza (coords.). Edad, discriminación y derechos (pp. 53-71). Cizur Menor: Thomson Reuters.

Cotino Hueso, L. (2020). Confinamientos, libertad de circulación y personal, prohibición de reuniones y actividades y otras restricciones de derechos por la pandemia del Coronavirus. Diario La Ley, 9608 (6). Disponible en: https:// bit.ly/2Tq73UW.

De Lora, P. (2005). ¿¿A qué inocentes debemos sacrificar? La selección de pacientes para la distribución de recursos sanitarios. Telos: Revista Iberoamericana de Estudios Utilitaristas, 14, 2, 9-32.

De Lora, P. (2020). ¿ ¿No es respirador para viejos? Sobre la «ética del bote salvavidas» y la COVID-19. Letras libres, 31. Disponible en: https://bit.ly/3kyQDpa.

De Miguel Beriain, I. (2020). Triaje en tiempos de pandemia: un análisis a partir de las limitaciones del marco jurídico español. En E. Atienza y J. F. Rodríguez (dirs.). Las respuestas del Derecho a las crisis de salud pública (pp. 229-241). Madrid: Dikynson.

De Montalvo, F. (2020). Pandemias, política y ciencia: el papel de la ciencia y los científicos en la solución de los conflictos derivados de la pandemia de la COVID-19, Cuadernos de Bioética (en prensa).

De Montalvo, F. y Bellver, V. (2020). La bioética en los tiempos del coronavirus: una reflexión acerca de algunos dilemas éticos-legales de la pandemia a partir del Informe del Comité de Bioética de España. En E. Atienza y J. F. Rodríguez (dirs.). Las respuestas del Derecho a las crisis de salud pública (pp. 243-264). Madrid: Dikynson.

Defensor del Pueblo (2020). Separata del Informe Anual 2019 Atención a personas mayores. Centros residenciales. Disponible en: https://bit.ly/2JbOFgE. 
Doménech Pascual, G. (2019). Sobre el poder explicativo del análisis económico del Derecho. En especial, del derecho de daños. InDret, 2. Disponible en: https:// doi.org/10.2139/ssrn.3414907.

Doménech Pascual, G. (2020). Responsabilidad patrimonial del Estado por la gestión de la crisis del COVID-19. El Cronista del Estado Social y Democrático de Derecho, 86-87.

Flores Giménez, F. (2020). Las personas mayores en la Constitución española: derechos y garantías. En B. Cardona, F. Flores y J. Cabeza (coords.). Edad, discriminación y derechos (pp. 29-52). Cizur Menor: Thomson Reuters.

García Amez, J. (2018). El acceso a la salud como derecho humano: los medicamentos esenciales. En Moura de Araujo et al. Direitos humanos universais (pp. 141-151). Lisboa: AAFDL.

Giménez Rodríguez, S. (2020). COVID-19 y personas mayores: ¿puede influir el aislamiento social en la enfermedad? The Conversation. Disponible en: https:// bit.ly/2HIyaYv.

Gómez Sánchez, Y. (2011). El derecho a la salud: un nuevo derecho de libertad. En S. Delgado Bueno y F. Bandrés Moya (coords.). Tratado de medicina legal y ciencias forenses. Derecho sanitario y medicina legal en el trabajo (pp. 3-17). Barcelona: Bosch.

HelpAge España (2020). Conclusiones y recomendaciones para el contexto español desde un enfoque basado en derechos. Disponible en: https://bit.ly/3moqp9i.

Junta de Castilla y León (2020). El impacto del COVID-19 en las residencias de personas mayores de Castilla y León y medidas adoptadas.

León Alonso, M. (2010). La protección constitucional de la salud. Las Rozas: La Ley.

Martínez Ques, A. A. (2015). La protección jurídica de las personas mayores desde la perspectiva de los derechos humanos. Revista de Derecho UNED, 17. 10671102. Disponible en: https://doi.org/10.5944/rduned.17.2015.16262.

Medina Alcoz, L. (2012). Mitos y ficciones en la responsabilidad patrimonial de las Administraciones públicas. Revista Española de Derecho Administrativo, 153, 153-181.

Pérez, J., Abellán, A., Aceituno, P. y Ramiro, D. (2020). Un perfil de las personas mayores en España, 2020. Indicadores estadísticos básicos. Informes Envejecimiento en Red, 25. Disponible en: https://bit.ly/3e1ELtt.

Pino, E. et al. (2020a). Gestión Institucional y Organizativa de las Residencias de Personas Mayores y COVID-19: dificultades y aprendizajes. Disponible en: http:// dx.doi.org/10.20350/digitalCSIC/12636.

Pino, E. et al. (2020b). Cómo reducir el impacto de la COVID-19 en las residencias de mayores. Agenda Pública. Disponible en: https://bit.ly/3jz3TsC.

Presno Linera, M. A. (2018). 40 años de Constitución y salud. Derecho y Salud, 28, 34-44. Disponible en: https://bit.ly/3dZXpSl.

Presno Linera, M. A. (2020a). Estado de alarma por coronavirus y protección jurídica de los grupos vulnerables. El Cronista del Estado Social y Democrático de Derecho, 54-65. Disponible en: https://bit.ly/37HaHlH. 
Presno Linera, M. A. (2020b). Estado de alarma y sociedad del riesgo global. En E. Atienza y J. F. Rodríguez. Las respuestas del Derecho a las crisis de salud pública (pp. 15-28). Madrid: Dikynson.

Rey Martínez, F. (2018). Protección de la salud, atención primaria y derechos fundamentales. Teoría y Realidad Constitucional, 41, 281-296. Disponible en: https:// doi.org/10.5944/trc.41.2018.22121.

Rubio, O. et al. (2020). Recomendaciones éticas para la toma de decisiones difíciles en las unidades de cuidados intensivos ante la situación excepcional de crisis por la pandemia por COVID-19: revisión rápida y consenso de expertos. Medicina Intensiva, 44 (7), 439-445. Disponible en: https://doi.org/10.1016/j. medin.2020.04.006.

Tenorio Sánchez, P. (2018). Derecho constitucional a la protección de la salud. En M. I. Álvarez y C. Vidal (coords.). La Constitución española: 1978-2018 (pp. 433-446). Madrid: Lefebvre El Derecho.

Truog, D., Mitchell, C. y Daley, G. (2020). The Toughest Triage: Allocating Ventilators in a Pandemic. New England Journal of Medicine, 382 (21), 1973-1975. Disponible en: https://www.nejm.org/doi/pdf/10.1056/NEJMp2005689.

Wang, H. et al. (2020). Dementia Care During COVID-19. The Lancet, 395 (10231), 1190-1191. Disponible en: https://doi.org/10.1016/S0140-6736(20)30755-8. 